\title{
ORIGINAL ARTICLE Effects of paraplegia on quality of life and family economy among patients with spinal cord injuries in selected hospitals of Sri Lanka
}

\author{
HHN Kalyani ${ }^{1}$, S Dassanayake ${ }^{1}$ and U Senarath ${ }^{2}$
}

Objectives: The study was conducted with the aim of assessing the effects of paraplegia caused by spinal cord injuries on the quality of life of patients and their family economy.

Study design: A descriptive cross-sectional study.

Setting: The study was carried out in Accident Service, Orthopedic and Neurosurgery Units of the National Hospital of Sri Lanka and the Spinal Injury Unit of Rehabilitation Hospital Ragama.

Methods: One hundred traumatic paraplegic patients were included as the study sample. Modified Ferrans and Powers quality of life index: spinal cord injury version was used to measure the quality of life. Pre- and post-family economic data were collected using an interviewer-administered questionnaire.

Results: Quality of Life was calculated under four major components. Paraplegics' family component $($ mean $=3.50)$ and social, economic aspects (mean $=3.24)$ are considerably good when compared with health and functioning $(m e a n=2.83)$ and psychological (mean $=2.78)$ components. Also the study revealed that expenditures are significantly high $(P=0.001)$ and income is significantly less $(P=0.001)$ after injury than before.

Conclusion: Quality of life is relatively good on family and social aspects, whereas the physical and psychological aspects are somewhat poor. Regarding family economy, expenses are significantly high and earnings are significantly less after the injury. Contribution to the income from self-employment shows the most significant decline. Findings suggest that the family economy of such patients should be supported.

Spinal Cord (2015) 53, 446-450; doi:10.1038/sc.2014.183; published online 4 November 2014

\section{INTRODUCTION}

Spinal cord injuries (SCI) are becoming more common at present and it is one of the most traumatic events to occur in an individual's life. Spinal cord damage below Thoracic 1 (T1) level is termed paraplegia ${ }^{1}$ and this may affect functions of lower limbs, trunk and pelvic organs, and may cause impairment of bowel, bladder and sexual function. ${ }^{2}$ This SCI brings sudden and profound life changes. It makes the person unable to engage in the recreational, social, educational and vocational activities. The rehabilitation may assist individuals to regain the capacity of performing activities of daily living (ADL), but the manner of doing them would be altered. During early hospitalization and rehabilitation, a person is likely to experience separation from his family members. Even after discharge, relationships with friends and family are likely to be different for them. ${ }^{2}$

Literature findings reveal that researches have traditionally focused on the disability assessment and management when working with persons with SCI. It is further important to evaluate quality of life (QoL), even though it has been suggested that the overall goal of rehabilitation programmes is to assist patients to enhance their QoL. Therefore, improving QoL following an SCI should be viewed as an important indicator in the promotion of health in a spinal injured patient. $^{3}$
QoL is defined as an individual's physical, emotional and social well-being, including their ability to function in the ordinary tasks of living. ${ }^{3}$ A study to assess the well-being of paraplegic Thai people, has defined QoL as living with independence, living with self-esteem and living well without suffering. ${ }^{4}$ Ferrans and Powers Quality of life index-spinal cord injury version is a commonly used measuring tool to assess QoL and a study has found that it clearly reflects the perspectives of persons with SCI. ${ }^{5}$

Traumatic paraplegia is most prominent among young men between the ages of 21 and 35 years, and therefore it is considered to be a relevant social problem that affects a part of the economically active population. ${ }^{6}$ According to Word Health Organisation, $20-40$ individuals per million of population acquire a SCI each year and $82 \%$ of them are male, while $56 \%$ of injuries occur between the age of 16 and 30 years. $50-60 \%$ out of them remain unemployed following injury. ${ }^{7}$ In consequence of SCI, person's ability to take financial care, particularly having an occupation and supporting the basic needs of the family will be disturbed. The expenses on medical care, nursing care and equipment may create financial difficulties. ${ }^{8}$

Persons with SCI are typically young, healthy men who were often physically active before being injured ${ }^{2}$ and they belong to the earning population of the country. They are the people who contribute to the

${ }^{1}$ Allied Health Sciences Unit, Faculty of Medicine University of Colombo, Colombo, Sri Lanka and ${ }^{2}$ Department of Community Medicine, Faculty of Medicine, University of Colombo, Colombo, Sri Lanka

Correspondence: HHN Kalyani, Allied Health Sciences Unit, Faculty of Medicine University of Colombo, 124/1, Barnes Place, Colombo 07, Western 00700, Sri Lanka. E-mail: nadeeshakalyani84@gmail.com

Received 15 July 2014; revised 28 September 2014; accepted 29 September 2014; published online 4 November 2014 
'family economy', which is defined as the basic structure of the production and consumption in a family which consists of loses and gaining. ${ }^{6}$ Ultimately this type of patients will have a great impact on family, especially having economic consequences. ${ }^{6}$ Even though many researchers have analyzed family adjustment to SCI, literature suggests that there are several major gaps in our knowledge with relates to economic consequences following a SCI especially related to the Sri Lankan setting and the current study has attempted to address that aspect.

Therefore, the aim of this study was to evaluate how the paraplegia affects a person's QoL and to identify the extent of impact related to different components in QoL. In addition this study was aimed at assessing the effect of paraplegia on family income and expenses in the family of affected in Sri Lanka.

\section{MATERIALS AND METHODS}

This descriptive cross-sectional study was conducted with 100 traumatic paraplegic patients at Accident Service, Orthopedic and Neurosurgery units of National Hospital of Sri Lanka (NHSL) and the Spinal Injury Unit of Rehabilitation Hospital Ragama (RHR). Study population was the patients who were admitted to the NHSL and RHR, diagnosed as paraplegia by the medical specialist in charge (ASIA Impairment Scale). ${ }^{9}$

Traumatic paraplegic patients, aged between 18 and 65 years, who were in their post-acute rehabilitation period were included to the study. Unconscious

Table 1 Socio-demographic characteristics of traumatic paraplegic patients $(n=100)$

\begin{tabular}{|c|c|c|}
\hline Characteristic & $n$ & Percentage (\%) \\
\hline \multicolumn{3}{|l|}{ Gender } \\
\hline Male & 85 & 85 \\
\hline Female & 15 & 15 \\
\hline \multicolumn{3}{|l|}{ Age group (years) } \\
\hline $18-25$ & 8 & 8 \\
\hline $26-35$ & 30 & 30 \\
\hline $36-45$ & 29 & 29 \\
\hline $46-55$ & 19 & 19 \\
\hline $56-65$ & 14 & 14 \\
\hline \multicolumn{3}{|l|}{ Type of lesion } \\
\hline Complete & 55 & 55 \\
\hline Incomplete & 45 & 45 \\
\hline \multicolumn{3}{|l|}{ Level of lesion ${ }^{a}$} \\
\hline T1-T8 & 28 & 28 \\
\hline T9-T12 & 40 & 40 \\
\hline L1-S5 & 32 & 32 \\
\hline \multicolumn{3}{|l|}{ Marital status } \\
\hline Married & 73 & 73 \\
\hline Unmarried & 22 & 22 \\
\hline Widowed & 3 & 3 \\
\hline Divorced & 2 & 2 \\
\hline \multicolumn{3}{|c|}{ Employment status $^{b}$} \\
\hline Unemployed & 9 & 9 \\
\hline Employed & 70 & 70 \\
\hline Self employed & 16 & 16 \\
\hline Retired & 5 & 5 \\
\hline
\end{tabular}

${ }^{\mathrm{a}} \mathrm{T}=$ Thoracic levels, $\mathrm{L}=$ Lumbar levels, $\mathrm{S}=$ Sacral Levels of the spinal cord. bBefore the injury. patients, patients in severe discomfort or confusion and paraplegia due to pathological cause were excluded. In addition, patients who did not have an insight to give a rational answer were excluded. Initial visit was made to each unit and all the patients who fulfilled the above criteria were included. Then visits were made at regular intervals as two weekly visits until the required sample was fulfilled. Prior to start data collection a pre-test was conducted using five paraplegic patients from each setting to find the understandability and time it takes to fill up the questionnaire. Two changes were made in the questionnaire to improve the understandability. 'Faith in god' was changed to 'faith in religion', because majority of Sri Lankans are Buddhists and the concept of 'god' does not exist in Buddhism. The 'sex life' was amended as 'expectation for a contented sex life' because paraplegics were still in hospital and cannot comment on sex life until they are discharged to homes.

Data were collected using an interviewer-administered questionnaire. Initially the formal translation of the questionnaire was done in the local language (Sinhala) and was administered to the patients in Sinhala. QoL was measured using the Ferrans and Powers quality of life index-spinal cord injury version. ${ }^{5}$ QoL components were scored on a scale of $1-5$ with 1 being very dissatisfied and 5 being very satisfied under the four subscales. The Health and Functioning subscale consisted fifteen items, Psychological/Spiritual subscale consisted seven items, Family subscale consisted six items and Social and Economic subscale consisted seven items. Mean score was calculated for each item and for each subscale.

Family income before and after the injury was assessed under nine subcomponents, which generally contribute to family income. Family expenditure before and after injury were assessed under eight sub-components. Mean income and expenditure before and after the injury was calculated for each component separately and finally as a total. In order to compare the pre- and post-injury values, paired sample $t$-test was used.

Data was analyzed using SPSS (Statistical Package for Social Sciences) software 18 th version, which is supplied by IBM Singapore.

\section{Statement of ethics}

Ethics clearance was obtained from the Ethics Review Committee, Faculty of Medicine, University of Colombo. Permission to conduct the study was obtained from the Directors of NHSL and RHR and the consultants in charge of the selected wards. Informed written consent was obtained from participants. No identification data were taken.

\section{RESULTS}

One hundred and sixteen subjects were examined to select 100 paraplegics to be eligible to participate in the study. Among the study sample, 85 patients were males and $59 \%$ of the patients represented the age group of 26-45 years. Majority were married (73\%). Out of 100 participants, 55 have got complete transaction of the spinal cord and the commonest affected region was T9-T12 region (40\%). Regarding their employment status, 70\% were found employed and among them $61 \%$ were males (Table 1 ).

\section{Quality of life}

QoL was assessed under four subscales and the family subscale shows the highest rating with a mean value of 3.50 indicating that paraplegics' satisfaction with relates to family components are good. (Table 2). Among its items, family health component, emotional support from the family and perception towards children have been rated high with means of $4.75,4.51$ and 4.02 respectively. The social and economic subscale has been rated the second highest with a mean of 3.24 (Table 3). Within that the highest rated item is the traumatic paraplegics' satisfaction towards their home $($ mean $=4.09)$. Health and Functioning Subscale and psychological/spiritual subscale have rated low with mean scores of 2.83 and 2.78 , respectively. In the health and functioning sub scale which consists of 15 items, the low rates are taken by sex life $($ mean $=2.03)$, ability to go place outside $($ mean $=$ $2.09)$, worries $($ mean $=2.18)$, things for fun $($ mean $=2.36)$ and 
chances for a happy future $($ mean $=2.51)$. The paraplegics' highest dissatisfied is the psychological and spiritual scale consisting seven items. The patient's self-concept is devaluated (mean $=2.08)$ as well as peace in mind $($ mean $=2.11)$ and happiness in general $($ mean $=2.31)$ are dissatisfied to a great extent. Even though most components rated low, the only aspect which remains satisfied is the faith patients have towards religion, which has been reported with a mean of 4.32 .

\section{Family income and expenditure before and after the injury}

A paired samples $t$-test revealed a statistically significant difference between the mean total income before the injury and total income after the injury $(P$-value $=0.001)$. The self income shows the most significant difference with a $P$-value of 0.001 . The remaining income sources do not show a significant difference. (Table 4). A paired samples $t$-test again revealed a statistically significant difference between the mean total expenditure before the injury and total expenditure after the injury $(P$-value $=0.001)$. The expenses for basic needs, medical expenses, rehabilitation cost and additional expenses show the most significant difference with $P$-values of 0.001 . Remaining expenses, such as expenses for spouse and children, maintenance paid and expenses on rents and utilities remain the same as before. (Table 5).

\section{DISCUSSION}

Researches have stated that paraplegia would have significant, perhaps devastating effects on QoL. But in contrast some paraplegic patients have stated that paraplegia has a relatively a small effect on their QoL. ${ }^{10}$ In fact, our study aims to find how this is experienced in Sri Lankan setup. Further, the impact on family economy, being a paraplegic is also discussed in this study.

The results revealed that the majority of traumatic paraplegics were males being $85 \%$ and in comparison the study by Khupantavee et al. ${ }^{4}$ has noted that the traumatic paraplegics were predominately men. With related to age, 26-45 years (59\%) was found to be the most common and similarly a Sri Lankan study by Chappell et al., ${ }^{7}$ has revealed that the great majority was from 35-40 years age group.

Approximately $73 \%$ of the sample were married indicates that this can have a huge impact on families. On the other hand majority of traumatic paraplegics being male highlights the fact that patient is mostly the bread winner of the family who is playing the role of the husband or the father. Before the injury $70 \%$ of paraplegics were employed and among them $16 \%$ were self-employed indicating the fact that majority of the sample belongs to economically active population and the injury would have a considerable impact on person's family economy.

With relates to QoL, studies have found that most paraplegics are highly satisfied from their family relationships and support they get from friends and peers. ${ }^{4}$ Those have stated that well-being for them is the family's well-being and importantly the children. In addition, friends, support groups or peer support were important human sources of support for paraplegics. ${ }^{4}$ Current study findings coincide with above facts as traumatic paraplegics have rated high on family and social aspects. They are highly contented on the emotional support from family (mean $=4.51)$, home environment $($ mean $=4.09)$ and about the children $($ mean $=4.02)$. In addition they are happy about their friends $($ mean $=3.88)$ and emotional support they get from peers $($ mean $=3.78)$. With relates to marital status studies reveal that the divorce rate after injury was found to be high and not having a spouse or a partner also have impacted negatively for the QOL, ${ }^{7}$ whereas in our study the participants do not show big dissatisfaction on not having a spouse or partner $($ mean $=3.34)$. 
Table 3 Overall mean scores for different subscales of QoL among traumatic paraplegic patients $(n=100)$

\begin{tabular}{lll}
\hline Sub scales to measure quality of life & Mean & s.d. \\
\hline Health and functioning subscale & 2.83 & 0.97 \\
Psychological/spiritual subscale & 2.78 & 1.02 \\
Family subscale & 3.50 & 0.91 \\
Social and economic subscale & 3.24 & 0.87 \\
\hline
\end{tabular}

Mean scores were calculated getting averages for different components of the subscales.

Table 4 Comparison of monthly family income before and after injury in traumatic paraplegic patients $(n=100)$

\begin{tabular}{lrrrrr}
\hline Source of income & Average income $(L K R)^{a}$ & $n$ & $\mathrm{P}^{b}$ \\
\cline { 2 - 3 } & & & \\
& Before injury & After injury & & \\
\hline Income from self-employment & 21566.00 & 5335.00 & 100 & 0.000 \\
Income from spouse's employment & 6160.00 & 6780.00 & 100 & 0.241 \\
Pension & 984.15 & 1190.40 & 100 & 0.220 \\
Income from any property & 3940.00 & 3860.00 & 100 & 0.557 \\
Interest from savings or other bank & 227.00 & 195.00 & 100 & 0.289 \\
account & & & & \\
Disability pension & 0.00 & 32.30 & 100 & 0.285 \\
Cash assistance from welfare & 16.00 & 578.50 & 100 & 0.106 \\
programme & & & & \\
Compensation/insurance before & 11.50 & 366.50 & 100 & 0.031 \\
Any other income & 32968.15 & 18723.70 & 100 & 0.001 \\
Total monthly income & & 1570.00 & 100 & 0.827
\end{tabular}

aThe US Dollar to Sri Lankan Rupee exchange rate in 2011 (average) was 1 USD $=114.0178$ LKR.

bPaired $t$-test was used to calculate significance between two means.

Having being able to go places outside the home gives a person a sense of relaxation and well-being and literature findings indicate that most outside places are inaccessible for persons with disabilities. Public and private environments are not adapted for them and these barriers have a negative impact on the QoL. 7 Current study findings also indicate that ability to go places outside is not satisfied by the majority. (Mean $=2.09)$ This is same with a study which mentions mobility as the top demand which has contributed for the lowest score for in physical health in paraplegics. In fact, it is achievable by providing more support for transport for people with paraplegia. They have stated that there should be more community support to provide transportation, medical care and social lives for these patients. ${ }^{11}$ However, they lacked support facilities such as ease of access to buildings and public transport indicating the problem with reentering the community or living, which in turn affects their sense of well-being. ${ }^{4}$

Paraplegia had lower QoL in the physical domain compared with other populations suggest that physical problems are a key factor affecting the general QoL of patients with paraplegia. ${ }^{11}$ When compared with the studies conducted worldwide, the Sri Lankan paraplegics' main emphasis was to make them independent for their ADLs. In a cultural background where strong family relationships exist, what they plead is not the affection and acceptance, but the physical independence. Regarding the ability take care of the own self is slightly dissatisfied in the current study (mean $=2.75$ ) and most are feeling that they have less energy $($ mean $=2.74)$. Therefore it is the responsibility of the clinicians and therapists to implement appropriate rehabilitation programmes to make them functionally independent.
Table 5 Comparison of monthly family expenditure before and after injury in traumatic paraplegic patients $(n=100)$

\begin{tabular}{lrrrrr}
\hline Source of expenditure & \multicolumn{2}{c}{ Average income $(L K R)^{a}$} & \multirow{2}{*}{$\mathrm{P}^{b}$} \\
\cline { 2 - 4 } & & & \\
\cline { 2 - 4 } & Before injury & After injury & & \\
\hline Expenses for basic needs & 12820.00 & 12173.00 & 100 & 0.001 \\
Maintenance paid & 1922.00 & 2225.50 & 100 & 0.207 \\
Expenses on spouse and children & 5830.00 & 5510.00 & 100 & 0.121 \\
(family members) & & & & \\
Payment for rents and utilities & 1510.00 & 1448.00 & 100 & 0.398 \\
Contribution for charity / social work & 1235.00 & 1142.00 & 100 & 0.010 \\
Medical expenses & 1322.00 & 3414.50 & 100 & 0.001 \\
Rehabilitation cost & 0.00 & 3715.00 & 100 & 0.001 \\
Any other expenses & 2575.00 & 9955.00 & 100 & 0.001 \\
Total monthly expenditure & 27214.00 & 39583.00 & 100 & 0.001
\end{tabular}

aThe US Dollar to Sri Lankan Rupee exchange rate in 2011 (average) was 1 USD $=114.0178$ LKR.

baired $t$-test was used to calculate significance between two means

In addition Khupantavee et al., ${ }^{4}$ state that paraplegics are frustrated about their limited activities and being unable to work. They have found that people with paraplegia, who can manage their affairs or physical functions of daily living, such as dressing, moving about, and using the toilet, gain a sense of well-being. Also in order to make the paraplegics more independent at home the family members can be trained to assist them with their self caring and also assistance for appropriate home modification can be given by the government. Introducing sexual counseling and adjustment strategies at community based level, once the patients are discharged to their homes is also important as they have scored very less on expectations for a contented sex life (mean $=2.03)$.

It is important to note that paraplegics' psychological aspect is found to be the least satisfied aspect with the lowest rating for the peace in mind (mean $=2.11$ ). Their general happiness is also slightly dissatisfied $($ mean $=2.31)$. These findings coincide with other studies that looked at the QoL of spinally injured individuals in different point of views. Thai paraplegics are with stress and worry as well as with feeling fear, frustration and helplessness. In terms of negative emotions, stress and worry concerning the consequences of SCI were the most prevalent psychological impacts reported. ${ }^{4}$ In order to address these issues in Sri Lanka psychological and peer-counseling can be introduced. Since Sri Lankans' lives are closely associated with Buddhism and other religions, the religious leaders can take part in counseling the patients at village levels; there by the paraplegics' spiritual aspect can be uplifted.

Several studies have indicated that there are significant costs incurred throughout the life of a person with SCI, including initial hospitalization and acute rehabilitation, home and vehicle modification, recurring costs for medical equipment, medication and personal assistance. ${ }^{11}$ Apart from that the traumatic paraplegics are mostly from the earning population of the country as discussed earlier and this indicates the fact that being a paraplegic causes a huge economic loss, as they are unable to engage in previous jobs to earn a living. Therefore all these facts imply that there is a considerable economic impact due to this condition.

During the comparison of pre- and post-mean family income and expenditures, post income has decreased $(P=0.001)$ and post expenditure has increased $(P=0.001)$ significantly. In relation, it was revealed that most patients who were self-employed show a drastic drop in their income after the injury, which had caused the most 
significant impact on family economy. ( $P=0.001)$ Very few had received cash assistance from compensation or insurance. None had received any disability pension even though it is happy to see the retired candidates receiving the pension even after the injury. The expenses for basic needs have gone higher and there were newly added medical expenses and rehabilitation cost. Further, there were lot of additional expensed added including care giver fees and transportation cost.

The 'Household Income and Expenditure Survey' conducted by the Department of Census and Statistics of Ministry of Finance and Planning, Sri Lanka for the years 2009/2010 ${ }^{12}$ has revealed the average Sri Lankan monthly house hold income as LKR 36451 and the average monthly house hold expenditure as LKR 31331 . (The US Dollar to Sri Lankan Rupee exchange rate on 11 December 2010 was 1 $\mathrm{USD}=110.570 \mathrm{LKR}^{13}$ ). The current study pre injury values are almost same with above values and it is important to notice that post-income values being significantly less and post-expenditure values being significantly high when compared with the above values indicating the fact that there is a huge economic consequence on family economy due to traumatic paraplegia.

In case of impact on family economy, studies related are rare to find. The studies available are those which explain the total expenses following an SCI. The study by Berkowitz in United States the average direct costs per person were $\$ 103000$ for hospitalization and home modifications during the first 2 years post injury and $\$ 14000$ per year thereafter for medical care. Losses in earnings and homemaker services averaged $\$ 12726$ per year. Total aggregate costs for 1 year were estimated at $\$ 5.6$ billion. Lifetime costs for a representative person with complete paraplegia injured at age 33 were estimated to be $\$ 500$ $000 .{ }^{11}$ In Thai society, economic problems or unemployment were seen as important obstacles and found that $58-70.9 \%$ of SCI patients were unemployed after hospital discharge. So, financial security and jobs emerged as important issues. ${ }^{4}$

These findings emphasize the fact that such families should be economically supported. If the spouse had not engaged in money making earlier, assistance can be given for them to do some earning to support the family. Government or nongovernmental organizations can implement ways to assist such families. Also there should be possible ways for disabled people to find feasible jobs for them. As their hand functions are not affected and as almost every one gains a good sitting balance they can be provided with suitable activities where they can earn a living. Further the employability of a paraplegic patient after rehabilitation has to be considered. Therefore opportunities can be created in the society to utilize their skills in order to make them contribute to the earning population.

The gender distribution of the current sample is unequal. In Sri Lankan setup the type of employment, income, head of house hold and so on are so different between men and women and the impact on family economy due to paraplegia has to be addressed separately for men and women. Therefore this can be mentioned as a limitation of the study. Another limitation is that the paraplegics were interviewed during post-acute rehabilitation period and it would be more reliable if interviews were conducted among the rehabilitated patients.

\section{CONCLUSION}

This study indicates that traumatic paraplegia is common among economically active male population. QoL is good on family and social aspects, while that of physical and psychological aspects are poor. Regarding family economy, expenditure is significantly high and earnings are significantly less after the injury than before. Post-injury contribution to income from the self-employment is significantly less. The findings emphasize the fact that such families should be economically supported, together with suitable income generating activities.

\section{DATA ARCHIVING}

There were no data to deposit.

\section{CONFLICT OF INTEREST}

The authors declare no conflict of interest.

1 Jacques E. A Spinal Cord Injury with Paraplegia [Internet]. 2014; [cited 2014 March 13]. Available from http://www.spinal-injury.net/paraplegia.htm.

2 Somers MF. Spinal cord injury- Functional rehabilitation. 2nd edn, New Jersey: Prentice-Hall, 2001; 54-75.

3 Wikipedia contributors. Quality of Life [Internet]. Wikipedia, The Free Encyclopedia 2011 Feb 19, 19:58 UTC [cited 2012 December 2]. Available from: http://en. wikipedia.org/w/index. php?title=Quality of Life\&oldid $=414830586$.

4 Khupantavee N, Songwathana P, Chuaprapaisilp A. A meaning of well-being: from the experience of paraplegic Thai people. Songkla Med J 2008; 26: 173-183.

5 Ferrans CE, Powers MJ. Scores for the quality of life index (QLI) - Spinal Cord injury version III [Internet] 1998 [cited 2013 Dec 13]. Available from: http://www.uic.edu/ orgs/qli/questionaires/pdf/spinalcordinjuryversionlli/Spinal3subscalesitems.pdf.

6 Young W. Effect of Spinal Cord Injury on Family Members. Care Cure community. [Internet] 2013 Mar 14; [cited 2013 Dec 13]. Available from: http://sci.rutgers.edu/ dynarticles/family_adjustment.pdf.

7 Chappell P, Wirz S. Quality of life following spinal cord injury for 20-40 year old males living in Sri Lanka. APDRJ 2003; 14: 162-178.

8 Blanes L, Carmagnani MI, Ferreira LM. Quality of life and self-esteem of persons with paraplegia living in Sao Paulo, Brazil. Qual Life Res 2009; 18: 15-21.

9 American Spinal Injury Association Impairment Scale [Internet] 2000 [cited 2013 Dec 13]. Available from: http://www.asia-spinalinjury.org/elearning/ISNCSCI_Exam Sheet_r4.pdf.

10 Joseph UY, Wong NF, John YW, Leong CY, Keith DK. Quality of life of traumatic spinal cord injured patients in Hong Kong. J Rehab Med Supp/ 2008; 40: 126-131.

11 Berkowitz M. Assessing the socioeconomic impact of improved treatment of head and spinal cord injuries. J Emerg Med 1993; 11: 63-67.

12 Sri Lanka. Household Income and Expenditure Survey - 2009/10. Department of Census and Statistics of Ministry of Finance and Planning, Sri Lanka. 2011 March, vol. 11, pp 6-15.

13 Central Bank of Sri Lanka - Current Economic Indicators: Exchange Rates. Sri Lanka [Internet] 2010 Nov 1 [updated 2014 Jan 1; cited 2014 Apr 8]. Available from: http:// www.cbsl.gov.lk/htm/english/_cei/er/e_1.asp. 